A preliminary analysis of the market for small, medium and large horticultural shows in England

Dorothy Fox and Jonathan Edwards

The School of Services Management

Bournemouth University

Correspondence to Dr Dorothy Fox

Dorset House, Fern Barrow

Poole, BH12 5BB

ENGLAND

dfox@bournemouth.ac.uk

Tel: $+44(0) 1202961578$

Fax: +44 (0)1202 515707 


\title{
A preliminary analysis of the market for small, medium and large horticultural shows in England
}

\begin{abstract}
Understanding the consumer is important in estimating the market for an event. This study analysed the socio-demographic and other characteristics of actual and potential visitors to three styles of English horticultural shows. The shows selected varied in terms of their status - national, regional, local; the number of visitors they attract and the length of time they are open to the public. The analysis of the findings of a survey of residents in southern England suggests that whilst age is a key demographic variable, a more valuable means of segmenting the population is by their level of enthusiasm for gardening. Furthermore it is proposed that demand for the largest shows, held nationally can be established not only, through these factors but also, by the potential visitors' history of attending smaller horticultural shows. The implications for the marketing of these and similar events are discussed.
\end{abstract}

\section{Keywords: horticultural shows; gardening; visitors; segmentation.}

\author{
Introduction
}

Events are unlikely to have universal appeal - successful event management therefore incorporates a process that matches the product with the market (Getz, 2005). Consequently, the identification of potential markets is essential before a marketing strategy can be developed. Whilst there is a growing body of research based upon 
visitor surveys, Getz and Cheyne (2002) have highlighted the need for more general market research into event participation, isolating specific types of event visits. Additionally, there has been little comparative research across event formats. Crompton and McKay (1997) examined visitation at a sample of various activities within a festival and Nicholson and Pearce (2001) made a comparative analysis of visitation at four very different events in South Island, New Zealand. Lee and Crompton (2003) discussed visitors to similar festivals in Ocean City, Maryland and Saayman and Saayman (2006) considered visitors to similar festivals but in different locations in South Africa. However, there appears to be no comparative examination of participation at events that have a similar appeal, but which vary considerably in status and size. This paper therefore seeks to extend the research on event participation by means of a study, which first, compares visitation at events of very different statuses and sizes, but having a common theme and secondly demonstrates how this knowledge can contribute to market segmentation.

Events that are variously known as horticultural shows or flower shows, are a long established tradition in England and are notable, not only for their popularity but for their disparate sizes. Size is often used to characterise events but definitions in the literature are rare and distinctions are blurred. Mega-events have been defined in terms of the number of visitors - exceeding 1 million and their capital cost - at least $\$ 500$ million (Getz, 2005), but there appears to be no other objective definitions of size of event. Bowdin et al. refer to 'hallmark events' as those that 'become so identified with the spirit or ethos of a town, city or region that they become synonymous with the name of the place, and gain widespread recognition and awareness' (Bowdin et al., 2006, p.17). They further distinguish events as either 
major or local/community events. The former they suggest are able to attract significant visitor numbers, media coverage and economic benefits, whilst local events can produce a variety of experiences, not only fun and entertainment but pride in one's community and a greater sense of belonging. Janiskee (1996, p. 404) defines local or community events as:

...family-fun events that are considered 'owned' by a community because they use volunteer services from the host community, employ public venues such as streets, parks and schools and are produced at the direction of local government agencies or nongovernment organisations (NGOs) such as service clubs, public safety organisations or business associations.

The horticultural shows discussed in this paper are difficult to assign to a size of event based on these definitions but an understanding of the markets for events requires some pragmatic means of distinguishing between event sizes. Events always have several stakeholders and one can talk in terms of the size of event, in relation to any one of them. Horticultural shows can therefore be considered in numerous ways including the volume of visitors, whether organised by amateurs or professionals, the number of exhibitors, the show's significance to local communities, the number of volunteers or employees engaged, the success in attracting the tourism market or the level of media exposure.

In this paper, horticultural shows are characterised as small, medium and large events, by the number of visitors. The 'small', locally significant shows attract visitors in the hundreds or low thousands. Medium-sized, often regionally significant, shows have 
an audience in the tens of thousands, whilst 'large', frequently national shows, are considered as those that attract over a hundred thousand visitors.

\section{Literature review}

The development of horticultural shows

Horticultural shows have a long history - records exist of flower shows in Japan about 900 A.D., with chrysanthemums being exhibited (Perry 1955). In Belgium, Europe's first large-scale plant and flower show was held in 1809 (Foire Internationale de Liège, 2003). Two decades later, the Pennsylvania Horticultural Society held the first major show in America, the Philadelphia Flower Show and by 1869 Germany's first International Horticultural Exhibition, with 420 exhibitors took place. The first International Horticultural Exhibition in England was held in the grounds of the Royal Hospital, Chelsea in 1911. It received 178,389 visitors and two years later, following on from this success, the Royal Horticultural Society held the first Chelsea Flower Show (Marsden-Smedley 1976).

Horticultural shows are now a worldwide phenomenon; Australia's largest show is the Melbourne International Flower and Garden Show, which attracts about 125,000 visitors. The show is owned by the Nursery and Garden Industry Victoria and the Victorian Farmers Federation (Flowers Victoria) and is staged within the WHO listed Royal Exhibition Building and the surrounding Carlton Gardens. Describing itself as a national 'Hallmark Event' it is the leading horticultural show in the southern hemisphere. In America, the Philadelphia Flower Show has over 275,000 visitors annually. Since 1996, it has been located in the Pennsylvania Convention Centre, where it encompasses 33 indoor acres, making it the largest indoor Flower Show in 
the world. In Asia, two shows, in Hong Kong and Laman, Malaysia, each attract over half a million visitors.

\section{Horticultural shows in England}

In England, many general horticultural shows began as fairs or as folklore festivals with the harvest fruit, vegetables and flowers forming a centrepiece (MarsdenSmedley 1976). Handloom weavers in the Midlands and the North of England began holding other shows in the later half of the eighteenth century. Their interest was in breeding and showing what were known as 'florists' flowers, that is flowers that had been raised or originated from seed in the garden of an enthusiast known as a 'florist' (Davies, 1991).

Small shows are the direct descendants of those held in the eighteenth and nineteenth centuries and are organised by volunteers from community horticultural societies, gardening clubs and allotment ${ }^{1}$ associations. Entry fees are usually minimal and visitor numbers are low. The visitors comprise local residents of the village or town and any tourists are likely to be incidental. Usually held in a community hall or small marquee, they display the flowers or vegetables amateur gardeners have grown to compete for nominal prizes. The members provide plants and refreshments for sale. That these events are extremely common is indicated by there being 61 of these shows in the county of Dorset in 2002. A typical example is the Kinson Horticultural Society Show, which began in 1907 and has about 700 visitors each year. Over the last century, however, these shows have gradually been supplemented by larger events.

\footnotetext{
${ }^{1}$ An allotment is a small area of land, traditionally about $277.5 \mathrm{~m}^{2} / 2,925 \mathrm{ft}^{2}$, not attached to a house that is rented by an individual for kitchen gardening.
} 
Medium-sized shows are usually professionally organised either by commercial operators or by larger horticultural societies and are frequently held at county showgrounds or in the grounds of country houses. Professional nurseries exhibit and sell plants to the public, although there may also be an amateur competition included. Garden furniture, equipment, craft exhibitors, refreshments, entertainment etc. are all sold or provided on a commercial basis. Typical examples are the Dorset Garden Show organised by an event production company and the Cardiff Flower Show managed by the Royal Horticultural Society (RHS), Britain's leading horticultural charity. The latter has an average annual attendance of 17,500 (H. Gray, RHS, personal communication, January 02,2007$)$. Although they receive a larger number of visitors there are comparatively fewer of these events than the small shows - only 4 in Dorset in 2002. Visitors come from surrounding counties and there may also be a small proportion of tourists. Entry costs are higher than at small shows but substantially lower than the large shows.

One of the largest and most well known horticultural shows in England is the Chelsea Flower Show. However, there are also several other shows, of similar size, including the Hampton Court Palace Flower Show and Tatton Flower Show. All are organised by the RHS, but whereas these other shows are about plants, the Chelsea Flower Show is also very much about people.

Members of the British royal family make a private visit to Chelsea on the preview day (Monday) and the show remains a central part of 'The Season'. It is '...the smartest social event in the English calendar...It's A-list and serious A-list, very serious people; they'll fight to get tickets' (Smith 2002, p. 6). This has led to the show 
being renowned not just for its horticulture, but also for social networking and corporate hospitality. Stephen Bennett, the show's director is quoted as suggesting that the corporate hospitality facilities are always fully booked in advance because Chelsea is 'the one event that the wives love to come to...while the guys are in the hospitality unit... the wives are out spending their money' (Smith, 2002). He estimated that the show generates sales of $£ 30$ - $£ 50$ million for the gardening industry and up to $£ 100$ million if additional tourism created by the appeal of the Show is taken into account (Smith, 2002).

All of the large shows, however, can be characterised first, by the temporary creation of show gardens that are fundamental to the shows appeal and consequent advertising and secondly, by the celebrities who attend. Some celebrities are there to promote a new flower variety, named after them, whilst others are famous names from the horticultural media. Pringle and Binet (2005) define a celebrity has having 'a clearly defined personality and reputation; they are known to be extremely good at something beyond appearing in advertising, and it is their outstanding skill in their chosen field of endeavour which has brought them into the public eye and made them an object of veneration and respect' (Pringle and Binet, 2005, p. 201-2). These shows therefore have added value through their association with the celebrity gardeners' image and reputation. This is seen most effectively at another national show, BBC 'Gardeners' World Live' which is co-organised by the RHS (with Haymarket Exhibitions Limited and the $\mathrm{BBC}$ ) and is promoted in association with a gardening magazine and television programme of the same name. Eighty per cent of visitors attend the show to get ideas and inspiration for their gardens (BBC Gardeners' World Live, 2008). This is reflected in the advertising of the show as 'for gardeners, by gardeners'. 


\section{The segmentation of event markets}

Whether the aim of an event is income generation and/or the achievement of social goals, organisers seeking to maximise the value of their event need to identify the people who are most likely to appreciate the particular event experience. Getz defines 'segmentation' as 'the identification of relatively homogeneous groups that can be targeted for competitive advantage and to meet destination goals' (Getz, 2005, p. 87). Market segments need to be measurable and accessible but the various means of segmenting suggested in the literature can have their limitations. Geographic segmentation is often cited and in terms of horticultural shows, small shows can be considered as local events and medium-sized shows as regional events, for both of which the target audience is 'contained' in a geographic area. However, at national or international events, the potential audience is too widely distributed to be accessible. Furthermore, at events where many potential attendees are tourists, their place of residence will not be in the event locality. Therefore for these events, other segmentation strategies may be preferable.

Alternatives include socio-demographic segmentation, which although widely used, can be problematic. For example socio-economic group reflects level of education and events that include cultural elements have greater appeal to those with the cultural capital (Bourdieu, 1979) to appreciate them. However, for events that offer a popular cultural or other type of experience, socio-economic group maybe of less value.

Position in the life cycle or life stage may be useful for some types of events, particularly when children may be enthusiastic about attending. There is no data available from this or other research regarding child attendance at English 
horticultural shows, but gardens in England have the lowest proportion of children visiting of all attraction types (VisitBritain, 2005). It is likely therefore that children will not be the prime movers to visit a horticultural show, in the way that they are to other events. Accordingly as a form of segmentation this too has its weaknesses. Personality and psychographic segmentation are further possibilities but they also can have serious limitations (Bowdin et al., 2006). It is questionable how effective segmenting people based on their shared values and attitudes or personality is, as it is impossible to know whether respondents' declared responses are felt or simply reflect cultural norms.

Geodemographics, for example ACORN (A Classification of Residential Neighbourhoods) used in the UK (CACI Market Analysis Group) classifies residential areas into six main categories with seventeen subgroups and fifty-six types. Based on post-codes and the 2001 Census data, it has particular benefits to event organisers where the context is home-based, for example D.I.Y. shows such as the Daily Mail Ideal Home Show held each year in London and possibly horticultural shows, where access to or ownership of a garden is usually common to a post code area. Targeting by lifestyle characteristics such as this would seem particularly effective if the event has a core attraction rather than an extensive range of experiences on offer.

There appears to have been no academic research that has identified the socialdemographic profile of visitors to horticultural shows in England. Visitor survey data obtained at three of the large shows is the only visitor data currently available (data supplied by the RHS is given in Table 1). This demonstrates that those who attended these large shows are predominantly female, mature in age and from the higher 
occupational groups. At the Chelsea Show, 19\% of visitors are from overseas; this figure falls to $2.4 \%$ at the Hampton Court Show (H. Gray, RHS, personal communication, February 22, 2007). In relation to garden visiting, Connell (2004) queries 'whether academics perceive gardens as unfashionable, apolitical or commercially insignificant, is unclear' (Connell, 2004, p. 230) and the same questions could be asked of horticultural shows.

\section{Method}

This research was undertaken as part of a wider study into visiting horticultural attractions in England as a consequence of the paucity of data regarding the visitors to these types of visitor attractions (some results pertaining to garden visitors are cited in Fox and Edwards, 2008). A self-completion survey by residents was chosen, as it would be inclusive of visitors and non-visitors to the various types of horticultural attractions.

\section{The survey population}

The population of the survey were the adult residents of the 'BH' postcode area, which covers East Dorset and a small segment of South-West Hampshire in Southern England. This area was chosen first, as there is a considerable range of horticultural attractions in the vicinity, including both small and medium-sized shows as discussed above and secondly, due to its familiarity and convenience to the authors. Ideally a totally random selection of individuals was required, but there were economic constraints to their selection. These constraints were overcome by identifying clusters based on postcodes. 
The UK is divided into 124 postcode areas that are further divided into districts, sectors and then units. There are approximately 15 households in each unit (Consignia PLC, 2002). The 'Small User File' in the computer software, Post office address finder, Version4, provided the postcodes for the BH area. Every residential address identified within those postcodes became part of a cluster in the sampling frame. Arber (2001) describes the advantages of the Postcode Address File as an easily accessible, convenient and cheap sampling frame. It is more up-to-date than the Electoral Register as the Post Office updates it quarterly. Its disadvantage is that there is no record of the number of adults or households to be found at an address. This research overcame that problem by selecting all households at all the addresses in the cluster. The computer-generated programme from the 'Small User File' randomly selected the number of postcodes determined by a pilot survey. Residents within the household were then selected on the basis of 'next birthday'.

\section{The survey instrument}

An eight-page questionnaire was designed with variables derived from the visitor attraction literature including that specific to garden visiting, (for example, Gallagher, 1983), together with the authors' personal experiences of horticulture attractions. The socio-demographic variables, asked in closed questions, were gender, age (in ten-year bands, subsequently recoded to $16-44,45-64$ and 65 or over) and the type of garden the respondent has access to (none, own garden, communal garden, allotment or roof terrace/balcony where plants are grown). The respondent's current or previous occupation was asked in an open question which was coded to one of the standard 
occupational groups, A to E (where A are higher managerial, administrative or professional workers through to E, casual or lowest grade workers).

To identify the respondents' enthusiasm for gardening, they were presented with 8 statements and asked to indicate which one they thought best described them. These statements varied from 'I am an enthusiastic gardener', through for example, 'I would like to do some gardening, but I don't have a garden or allotment' and 'I don't really like gardening, but I do it to help another member of the household' to 'I don't like gardening and I don't do any'. These were then recoded into the 3 categories of enthusiastic, willing and unwilling gardeners.

Respondents were also asked whether they had ever visited a range of horticultural attractions, including inter alia, horticultural shows. The following descriptions were given of large, medium and small horticultural shows:

'The first type of show, I will call a celebrity show. They are very large shows, with gardening celebrities, show gardens etc.'

'The next type of show is not quite so large. I will call it a professional show, because it has professional exhibitors selling plants and gardening equipment etc. but no show gardens. They are often held in the grounds of stately homes.'

'The last type of show I will call an amateur show. This is the kind of show, which is held in a community hall or marquee. Gardeners compete for prizes, for the flowers or vegetables, they have grown.' 
For those who had never attended a particular type of show, a subsequent question asking, if it were possible, would they like to attend, was included. Finally, they were asked the number of visits to each category of show they had made that year $(0,1-2$, 3-4 and 5 or more). Almost all horticultural attractions in England are open in the spring, summer or autumn and so the visiting 'season' was over at the time of the survey.

\section{Procedure}

Questionnaires can be posted with a return stamped addressed envelope or delivered and collected. Personal delivery offers the opportunity for face-to-face contact, which can increase the response rate (Arber, 2001) and so this method was employed. A copy of the questionnaire and cover letter were delivered to each address, additionally where a householder was at home the researcher further explained the nature of the survey. The questionnaire was collected about 3 days later with a 'reminder' letter left at any household, where a questionnaire was not obtained. (Pre-notification or a second follow up letter could not be incorporated due to time and financial constraints.) Using a cluster sample reduced the distances travelled between respondents, whilst still maintaining a representative sample of the population.

Following the completion of a pilot study, the survey was delivered to the homes of 932 residents in November/December 2002. A total of 345 questionnaires were completely or partially completed, (58 in response to the 'reminder' letter) giving a response rate of $37 \%$. All were collated, including those that were only partially 
completed. Data was entered into the SPSS software package and analysis was carried out using chi-square to a $95 \%$ confidence level.

\section{Results}

The findings demonstrate that horticultural shows in England have considerable appeal. Just over half of respondents had at some time visited a small, 'amateur' show, slightly fewer had attended a medium-sized 'professional' show and just under a quarter had been to a large 'celebrity' show (percentages are shown in Table 2).

Table 2 also presents a cross-tabulation of the socio-demographic characteristics of respondents and their attendance at shows. Each figure therefore represents the percentage of respondents of that demographic that had visited each size of show. This indicates that horticultural shows appeal to both men and women. However, visitation increased with age at each size of show, with the small shows having the most pronounced differences between the age groups. (The value of $p$ in the $\mathrm{chi}^{2}$ test $=$ 0.000; statistically, a highly significant finding). Although there were no statistically significant differences between the occupational groups, the middle groups $(\mathrm{C} 1, \mathrm{C} 2)$ had visited large and medium-sized shows more than the higher and lower groups, but at the small shows, visiting increased with decreasing level of occupational group.

Getz and Cheyne (2002) suggest that there is often a potential connection between almost any hobby or leisure pursuit and special events. Therefore the data was analysed to assess if there was any relationship between attendance and the related leisure interest of gardening. Perhaps predictably in view of the content of the shows, 
the record of having visited each of the show types increased with the respondents' enthusiasm for gardening, all with statistically significant differences.

Additionally respondents were asked about their access to or ownership of a garden. However, the responses showed that garden 'ownership' is extremely prevalent in the area in which the survey was undertaken and the minority of respondents without access to a garden (5\%) was too small to make any analysis of this variable of use.

Comparison with the visitor surveys carried out at the large RHS shows (as detailed in Table 1 above) revealed a major difference to the findings of the resident survey. The RHS data indicates a marked imbalance between the genders with more women than men, visiting the large RHS shows, whereas the resident survey shows a much smaller difference between the genders. However in terms of age and occupational group the two surveys offer similar findings, with visitors more often from the middle and higher occupational groups and mature in age.

In order to assess the unmet demand for shows, respondents who had no previous history of visiting a category of show were asked whether they would like to visit each type, if it were possible. As Table 3 indicates, about half the respondents who had not already visited a large show would like to visit; $40 \%$ and $26 \%$ expressed a similar desire in relation to medium and small shows respectively.

Furthermore, the data indicated that for each characteristic there were statistically significant differences between the groups who would like to visit a large show, with three quarters of enthusiastic gardeners who had not visited showing that nonetheless 
they would like to attend. Perhaps predictably, a pattern also emerged that suggests the less willing the gardener, the less likely their interest in visiting any type of show, regardless of size.

Respondents were also asked which size show they had attended in the year of the survey. Unsurprisingly, in view of the number of respondents who had ever visited each size of show, more respondents had visited a small show that year (34\%), than either a medium-sized show (30\%) or large show (14\%). Further scrutiny revealed that $32 \%$ of respondents had attended shows of two different sizes and $12 \%$ had been to all three. Therefore, the data was analysed to establish how much commonalty there is between show visiting. This established that $40 \%$ of the visitors to the medium-sized shows had also visited the large shows at some time (Table 4). This figure rose to over half of respondents who had previously visited a large show and had also attended a medium-sized show in the year of the survey. Similar but smaller proportions were found in relation to having visited the small shows ( $30 \%$ of visitors to large shows). This confirmed that the shows have common appeal to visitors in offering a similar range of benefits and experiences.

Finally therefore, the data was analysed to assess whether demand for large shows varied by current attendance at horticultural shows. It was shown above that of all the respondents who had not previously attended a large show $50 \%$ would like to do so. Table 5 demonstrates that this figure rises to $58 \%$ of respondents who have visited a medium-size show and $55 \%$ of respondents who have attended a small show. However, when the data of respondents who had visited these shows in the year of the survey is considered, much larger and statistically significant differences emerge 
between those who are current visitors to shows and would like to attend a large show and those respondents who have not visited a medium-size or small show that year. The percentages of these respondents are $71 \%$ and $64 \%$.

As only $14 \%$ of respondents had visited a large show in 2002 , compared to $23 \%$ who had ever attended this type of show, the figures in Table 6 suggest that current visitors at medium and small shows could be a better indicator of demand for the large shows, than past visitors to them.

Conclusions and discussion

The literature suggests that segmentation of an event's market is a valuable tool in event marketing. This study has considered three ways of characterising actual and potential visitors to small, medium and large horticultural shows. It has demonstrated first, that the conventional means of segmentation by socio-demographic characteristics is not without some value in respect of these shows. Variation in age is reflected in statistically significant differences in attendance at all three sizes of horticultural show. Whereas the variables, gender, age and occupational group can be relevant in identifying potential visitors to large shows, only age is important in respect of medium-sized shows. However, none of these three variables showed any significant differences between actual and potential visitors to the small shows.

Secondly the study has shown that segmenting the market using a lifestyle characteristic, in this case the respondents' enthusiasm for gardening - a leisure pursuit that is clearly connected to the context of horticultural shows, has value for all 
three sizes of show. In each size category there were statistically significant differences between the types of gardener and both their actual or potential attendance at the shows (Tables 2 and 3). The greatest difference was for the large horticultural shows, where $51 \%$ of enthusiastic gardeners have visited this type of show, compared to only $18 \%$ of willing gardeners and $5 \%$ of unwilling gardeners.

Finally, this study extended the range of segmentational characteristics by demonstrating that attendance at small or medium-size shows is an additional variable worthy of consideration when segmenting the market for large horticultural shows. First, it was necessary to confirm that there is commonality of visiting between the shows of different sizes. The data above proves that not only did respondents visit different size shows at some point in their lives, but also they visited shows of varying size within the same year. The results then went on to demonstrate that differentiation within a population based on past attendance at smaller shows is useful in identifying the market for larger shows. Significantly, current attendance is of more value than past attendance.

Whilst at both the Chelsea and Hampton Court Flower Shows, visitor numbers are limited on safety grounds and tickets for both shows sell out each year, for the other large RHS shows and for the commercial operators who are currently developing the medium-size horticultural shows, attracting visitors is essential for economic success. The RHS's Tatton Park Show, for example, suffered a fall in numbers in 2007 to 82,000 (N. Childsclarke, RHS, personal communication, February 08, 2008) from 91,000 in 2006. For these shows, effective marketing is therefore critical. For the small shows, success is equally important to safeguard their existence in a time of 
decline. Further recognition of the links between the shows of all sizes is therefore imperative not only for the marketing of the larger shows, but for the very survival of the smaller, local horticultural shows, which are an essential part of our English heritage.

This research is a preliminary analysis of the market for three types of horticultural show in England and events of very different sizes have been described in this paper. Whilst the large shows may attract much greater visitor numbers than the mediumsized or small shows, they all offer benefits for the people who visit and as Watt (1998) cautions, 'The importance of an event should not be judged simply by its level, local or international; its standard, novice or advanced; or simply the numbers taking part' (Watt, 1998, p. 3). Any understanding of the relationships between visiting patterns of different size events that have a broadly similar appeal can only add to the effectiveness of the marketing strategies for all sizes of events.

\section{Limitations and future research}

The findings presented may reflect the area of southern England from which the sample was drawn and which may not be representative of the whole country. Dorset has an above average level of garden 'ownership' and data from the Mintel International Group Limited (2006), a consumer, media and market research group, shows that a greater proportion of adults had visited a garden for a day out in the previous 12 months than in the rest of England. The variation in the data in Table 1 between visitors to the London shows and to the Tatton Park Show in the north of England also supports the view that there are differences in the characteristics of 
visitors to horticultural attractions geographically in England. Therefore it would now be useful if further research across the country and in other event formats could be carried out to ascertain if the same approach reveals similar value.

This research has provided data from a survey of residents and it was therefore useful to compare it to the available data of actual visitors to the large shows organised by the RHS. The differences in gender between the two surveys are interesting as it suggests that women are perhaps more frequent visitors to the large shows. Further investigation is therefore needed to establish whether they are visiting more of the large shows each year or whether they visit a single show but more regularly each year.

\section{References}

Arber, S. (2001). Designing samples, In N. Gilbert, (Ed.), Researching social life, $\left(2^{\text {nd }}\right.$ ed., pp. 58-82). London: Sage Publications Limited.

BBC Gardeners' World Live, 2008. Exhibiting. Available from: http://www.bbcgardenersworldlive.com/bbcgwl/show_link12.asp [Accessed 12 February 2008].

Bourdieu, P. (1979). Distinction: a social critique of the judgement of taste. (Translation by: R. Nice, (1984), La distinction, critique sociale du jugement.) London: Routledge and Kegan Paul Ltd.

Bowdin, G., Allen, J., O’Toole, W., Harris, R. \& McDonnell, I. (2006). Events management, ( $2^{\text {nd }}$ ed.). Oxford: Butterworth-Heinemann. 
Connell, J. (2004). The purest of human pleasures: the characteristics and motivations of visitors in Great Britain. Tourism management, 25 (2), 229-247.

Consignia PLC. (2002). Postal address book. Edinburgh: Consignia PLC.

Crompton, J.L. \& McKay, S.L. (1997). Motives of visitors attending festival events. Annals of tourism research, 24 (2), 425-439.

Davies, J. (1991). The Victorian flower garden. London: BBC Enterprises Limited.

Foire Internationale de Liège (2003). Floralies internationales de Liège, 2003. Available from: $\quad$ http://www.floraliesliege.be/en/keepinframe.php?content $=02$ [Accessed 24 March 2007]

Fox, D. \& Edwards, J. (2008). Managing Gardens. In: A. Fyall, B. Leask, S. Garrod \& S. Wanhill (Eds.), Managing visitor attractions, (2 ${ }^{\text {nd }}$ ed., pp. 217-236). Oxford: Butterworth Heinemann.

Gallagher, J. (1983). Visiting historical gardens: a report on contemporary garden visiting and its literature. Leeds: Leeds Polytechnic.

Getz, D. (2005). Event management and event tourism (2 $2^{\text {nd }}$ ed.). New York: Cognizant Communication Corporation.

Getz, D. \& Cheyne, J. (2002). Special event motives and behaviour. In C. Ryan, (Ed.), The tourist experience ( $2^{\text {nd }}$ ed., pp 137-155). London: Continuum.

Janiskee, R. (1996). Historic houses and special events. Annals of leisure research, 23 (2), 398-414.

Lee, S. \& Crompton, J.L. (2003). The attraction power and spending impact of three festivals in Ocean City, Maryland. Event management, 8 (2), 109-112.

Marsden-Smedley, H. (1976). The Chelsea flower show. London: Constable and Company Limited. 
Mintel International Group Limited (2006). Days out - UK - April 2006. [online]. Available from:

http://reports.mintel.com/sinatra/reports/search results/show\&\&type=RCItem\&page=

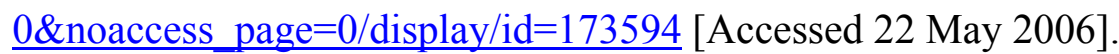

Nicholson, R.E. \& Pearce, D.G. (2001). Why do People Attend Events: A Comparative Analysis of Visitor Motivations at Four South Island Events. Journal of Travel Research, 39 (4), pp 449-460.

Perry, F. (1955). The woman gardener. London: Hulton Press.

Pringle, H. \& Binet, L. (2005). How marketers can use celebrities to sell more effectively. Journal of consumer behaviour, 4 (3), 201-214.

Saayman, A. \& Saayman, M. (2006). Sociodemographics and visiting patterns of arts festivals in South Africa. Event management, 9 (4), 211-222.

Smith, L. (2002). Chelsea Flower Show grows into top social event. The Times, 18 May, p.6a-h.

VisitBritain (2005). Attractions' Sector Structure and Visits in 2004. [online]. Available from:

http://www.tourismtrade.org.uk/Images/Sector $\% 20$ structure $\% 20$ and $\% 20$ visits $\% 20$ by \%20attraction\%20category\%202004 tcm12-17234.xls.pdf. [Accessed 23 January 2006].

Watt, D.C. (1998). Event management in leisure and tourism. Harlow: Addison Wesley Longman Limited. 
Table 1

The visitors to 'large’ Royal Horticultural Society shows in 2006

\begin{tabular}{|c|c|c|c|}
\hline Flower Show & Chelsea & Hampton & Tatton Park \\
& & Court & \\
\hline Number of visitors & 157,000 & 160,000 & 91,000 \\
\hline Gender - male & $29 \%$ & $28 \%$ & $33 \%$ \\
\hline female & $71 \%$ & $72 \%$ & $66 \%$ \\
\hline Average age & 51 & 53 & 52 \\
\hline Social group ABC1 & $74 \%$ & $83 \%$ & $86 \%$ \\
\hline Average household income & $£ 64,000$ & $£ 55,000$ & $£ 49,000$ \\
\hline
\end{tabular}

Source: The Royal Horticultural Society

Table 2

Previous attendances at horticultural shows (\% of respondents)

\begin{tabular}{|c|c|c|c|c|c|c|c|}
\hline \multicolumn{2}{|l|}{ Shows ever visited } & \multicolumn{2}{|c|}{ 'Large' show } & \multicolumn{2}{|c|}{ 'Medium' show } & \multicolumn{2}{|c|}{ 'Small' show } \\
\hline & & $(\%)$ & $p$ & $(\%)$ & $p$ & $(\%)$ & $p$ \\
\hline & All & 22.7 & - & 42.0 & - & 52.1 & - \\
\hline \multirow[t]{2}{*}{ Gender } & Male & 20.3 & & 44.6 & & 47.9 & \\
\hline & Female & 24.0 & & 40.1 & & 54.2 & \\
\hline \multirow[t]{3}{*}{ Age } & $16-44$ & 11.2 & \multirow[t]{3}{*}{0.000} & 31.4 & \multirow[t]{3}{*}{0.023} & 31.8 & \multirow[t]{3}{*}{0.000} \\
\hline & $45-64$ & 19.7 & & 42.1 & & 51.8 & \\
\hline & $\geq 65$ & 37.3 & & 51.6 & & 70.0 & \\
\hline \multirow[t]{3}{*}{ Occupational Group } & $\mathrm{AB}$ & 16.5 & \multirow[t]{3}{*}{-} & 41.4 & \multirow[t]{3}{*}{-} & 46.7 & \multirow[t]{3}{*}{-} \\
\hline & $\mathrm{C} 1 \mathrm{C} 2$ & 29.1 & & 45.8 & & 55.0 & \\
\hline & $\mathrm{DE}$ & 20.4 & & 34.7 & & 59.2 & \\
\hline \multirow[t]{3}{*}{ Type of gardener } & enthusiastic & 51.4 & \multirow[t]{3}{*}{0.000} & 62.0 & \multirow[t]{3}{*}{0.000} & 64.9 & \multirow[t]{3}{*}{0.000} \\
\hline & willing & 18.3 & & 43.9 & & 55.9 & \\
\hline & unwilling & 4.6 & & 15.6 & & 26.2 & \\
\hline
\end{tabular}


Table 3

Unmet demand for horticultural shows (\% of respondents)

\begin{tabular}{|c|c|c|c|c|c|c|c|}
\hline $\begin{array}{l}\text { Would like to } \\
\text { visit }\end{array}$ & & $\begin{array}{l}\text { 'Large' } \\
\text { show }\end{array}$ & & $\begin{array}{c}\text { 'Medium' } \\
\text { show }\end{array}$ & & $\begin{array}{l}\text { 'Small' } \\
\text { show }\end{array}$ & \\
\hline & & $(\%)$ & $p$ & $(\%)$ & $p$ & $(\%)$ & $p$ \\
\hline & All & 50.6 & & 39.5 & & 26.1 & \\
\hline \multirow[t]{2}{*}{ Gender } & Male & 39.6 & \multirow[t]{2}{*}{0.006} & 26.6 & \multirow[t]{2}{*}{0.009} & 19.0 & \multirow[t]{2}{*}{-} \\
\hline & Female & 57.6 & & 46.3 & & 31.1 & \\
\hline \multirow[t]{3}{*}{ Age } & $16-44$ & 57.7 & \multirow[t]{3}{*}{0.030} & 40.7 & \multirow[t]{3}{*}{-} & 26.2 & \multirow[t]{3}{*}{-} \\
\hline & $45-64$ & 53.8 & & 42.1 & & 33.9 & \\
\hline & $\geq 65$ & 36.5 & & 34.0 & & 10.0 & \\
\hline \multirow{3}{*}{$\begin{array}{r}\text { Occupational } \\
\text { group }\end{array}$} & $\mathrm{AB}$ & 39.2 & \multirow[t]{3}{*}{0.018} & 27.8 & \multirow[t]{3}{*}{-} & 26.5 & \multirow[t]{3}{*}{-} \\
\hline & $\mathrm{C} 1 \mathrm{C} 2$ & 60.8 & & 47.4 & & 58.8 & \\
\hline & $\mathrm{DE}$ & 53.8 & & 42.4 & & 14.7 & \\
\hline \multirow{3}{*}{$\begin{array}{r}\text { Type of } \\
\text { gardener }\end{array}$} & enthusiastic & 77.1 & \multirow[t]{3}{*}{0.000} & 70.4 & \multirow[t]{3}{*}{0.000} & 39.1 & \multirow[t]{3}{*}{0.025} \\
\hline & willing & 52.1 & & 41.4 & & 30.4 & \\
\hline & unwilling & 32.3 & & 16.7 & & 12.5 & \\
\hline
\end{tabular}


Table 4

Commonality of horticultural show visiting (\% of respondents)

\begin{tabular}{|l|c|c|c|}
\hline \multirow{2}{*}{ Horticultural shows visited } & \multicolumn{2}{|c|}{ 'Large' show } \\
\cline { 3 - 4 } & & \multicolumn{2}{|c|}{ Have visited } \\
\cline { 3 - 4 } & & $(\%)$ & $p$ \\
\hline 'Medium-sized' show & Have visited & 39.1 & 0.000 \\
\cline { 3 - 4 } & Have visited in 2002 & 50.6 & 0.000 \\
\hline 'Small' show & Have visited & 29.8 & 0.002 \\
\cline { 3 - 4 } & Have visited in 2002 & 31.4 & 0.000 \\
\hline
\end{tabular}

Table 5

Demand for 'large' horticultural shows from visitors to smaller shows (\% of respondents)

\begin{tabular}{|l|c|c|c|}
\hline \multirow{2}{*}{ Horticultural shows visited } & \multicolumn{2}{|l|}{ 'Large' show } \\
\cline { 3 - 4 } & \multicolumn{2}{|l|}{ Would like to visit } \\
\cline { 3 - 4 } & & & \\
\hline 'Medium-sized' show & Have visited & 57.7 & - \\
\cline { 3 - 4 } & Have visited in 2002 & 71.4 & 0.005 \\
\hline 'Small' show & & 54.7 & - \\
\hline & Have visited & 63.8 & 0.011 \\
\hline
\end{tabular}

